\title{
Observations upon the Cytology of Corynebacteria and Mycobacteria
}

\author{
By K. A. BISSET \\ Department of Bacteriology, University of Birmingham
}

SUMMARY: Bacilli in young cultures of Corynebacteria and Mycobacteria are multicellular. The individual cells are almost spherical, and a single bacillus may contain from one to twelve or more units. Reproduction may take place by division of the constituent cells, followed by simple fission of the bacillus, or alternatively by fragmentation into single cells which subdivide without separating, and grow into multicellular bacilli once more. The latter phenomenon may account for previous descriptions of life cycles in these genera.

The nuclear units are small, spherical granules, resembling those of some species of cocei. The characteristic morphology of Corynebacteria and Mycobacteria is an artefact, resulting from drying and heat-fixation. These genera do not appear to possess any morphological characters in common with the true Actinomyces, with which they are at present classified.

In the study of the morphology of the Corynebacteria great confusion has been caused by attempts to interpret the appearance of Corynebacterium diphtheriae when stained by the various diagnostic methods which have been employed in routine work. It is not proposed to attempt to review the literature on the nature of the metachromatic granules which has accumulated in the last 50 years, most of which ignores the fallacy of attempting to base cytological conclusions upon the evidence of heat-fixed material. Various members of the group have also been described as 'barred' in appearance, and it is the opinion of the author that these two characteristics have often been confused. In the Mycobacteria also, both granules and barring have often been described. Porter \& Yegian(1945) have shown that the granules in Mycobacterium tuberculosis are staining artefacts, and have also demonstrated chromatinic bodies in this organism, by Robinow's method. Brieger \& Robinow (1947) have confirmed this latter observation in the avian type of bacillus. Discrete Feulgen-positive granules have also been observed in $\boldsymbol{M}$. tuberculosis by Epstein, Ravich-Birger \& Svinkina (1936). Brieger \& Robinow (1947) tried to demonstrate the transverse septa which consideration of its morphology led them to expect in this organism, but failed to do so. In the present paper it is intended to show that these septa do in fact exist. They also appear quite clearly in an electron micrograph by Brieger, Crowe \& Cosslett (1947), although their presence is not commented upon in the text. The similar multicellular structure of $C$. diphtheriae is demonstrated by Burdon (1946) in drawings intended to illustrate the lipid content of the organism.

Materials and methods. The bacteria employed were freshly isolated strains wherever possible, and were grown upon routine culture media. Preparations were stained by Robinow's (1945) methods for nuclear materials and cell walls. Wet preparations were used throughout. 


\section{Observations}

A large number of preparations were made from eight strains of $C$. diphtheriae (four gravis, two mitis two intermedius) isolated from routine throat swabs. When stained by Neisser's stain these showed the characteristic morphology of the species, with obvious metachromatic granules (Pl. 1, fig. 1). When stained by tannic-acid-violet, they appeared much larger and were seen to consist of from one to six or seven almost-spherical cells (Pl. 1, fig. 2). Acid-Giemsa preparations showed that each cell was occupied by strongly

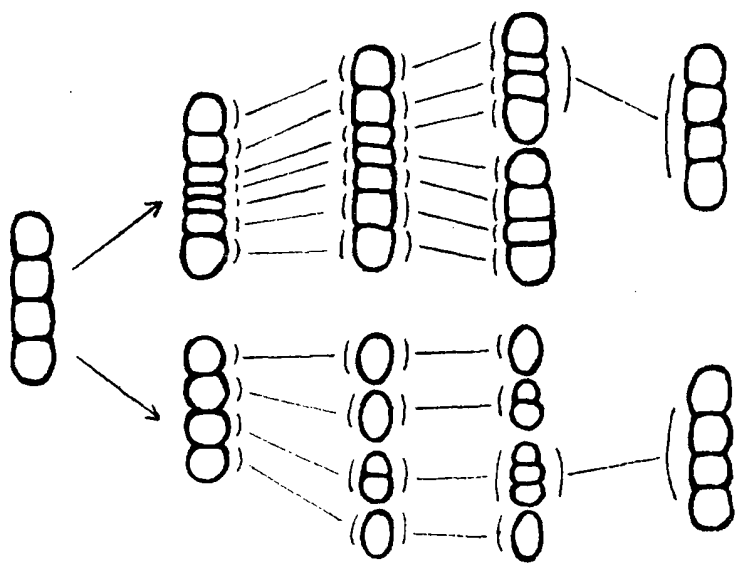

Fig. 1

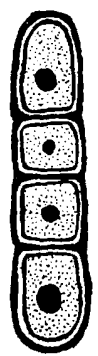

A

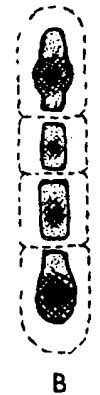

Fig. 2

Fig. 1. Mycobacterium or Corynebacterium. Alternative modes of reproduction. Above. Division of bacillus preceded by multiple cell division. Below. Fragmentation and regeneration from individual cells.

Fig. 2. Corynebacterium diphtheriae. A. Interpretation of actual morphology. B. 'Typical' morphology as produced in fixed, dried preparations. Note the effect of shrinkage.

stained protoplasm containing a small central granule (Pl. 1, figs. 3, 4). Other Corynebacteria of human origin, which did not exhibit metachromatic granules when stained by Neisser's stain, showed the same cytological appearances (Pl. 1, figs. 5, 6). These included two strains from the nasal passage and two from the vagina. The granule divided before the cell, and its appearance was very similar to that of the nuclear granules which have been reported in some cocci (Knaysi, 1942; Bisset, 1948). These appearances were best seen in young cultures; after 18 to $24 \mathrm{hr}$. growth they became difficult to stain.

Two methods of reproduction appeared to occur (Fig. 1). Division of the bacillus was sometimes preceded by cell division, producing a stage with a large number of small cells which then divided into two normal bacilli. Alternatively the bacillus was sometimes observed in the process of fragmentation into its constituent cells, from which, by growth and cell division, the bacilli were reformed. These two methods of reproduction occurred simultaneously in a single culture.

The Mycobacteria which were examined were stock cultures of $M$. tuberculosis 
(cold-blooded) and $M$. phlei, and one newly isolated strain of $M$. tuberculosis (human). All were difficult to stain; but a preliminary treatment with warm $70 \%$ ethanol rendered them more readily stainable. The resemblance of their cytological structure to that of the Corynebacteria was very great (Pl. 1, figs. 7-10). The tubercle bacilli also consisted of one to twelve or more small cells, each containing a chromatinic granule, although the latter, because of its small size, was difficult to resolve.

\section{DISCUSSION}

The 'characteristic morphology' of $C$. diphtheriae appears to be an artefact. The barred appearance of this species, and also of the tubercle bacillus, in dried, heat-fixed films, is due to shrinkage of the individual cell-contents away from the cell wall, producing gaps between them (Fig. 2). The metachromatic granules are probably mere condensations of stainable material within the dried cell. The present study has not attempted to add to the already considerable mass of contradictory evidence upon the nature of the material of which these metachromatic granules are composed. They do not correspond to the nuclear granules, as these are present in other types of Corynebacteria which do not exhibit metachromatic staining. It is probable, however, that the metachromatic material accumulates around the nuclear granules, as indicated in the diagram.

Some of the life-cycle theories which have been suggested in the tubercle bacillus may well be based upon observations of a system of reproduction involving fragmentation of the bacilli into their constituent cells. This multicellular structure has also a bearing upon reports of true branching in these genera. None of the strains examined possessed a cytological structure resembling that of the sporing Actinomyces as described by Klieneberger-Nobel (1947), in which the individual cell is branched. Nor do the branching tubercle bacilli illustrated by Brieger \& Robinow (1947) appear to possess such a structure. There seems little morphological basis for the belief that the 'higher bacteria' are related to the true Actinomyces.

\section{REFERENCES}

Bisset, K. A. (1948). The cytology of the Gram-positive cocci. J. gen. Microbiol. 2, 126-30.

Brieger, E. M., Crowe, G. R. \& Cosslett, V. E. (1947). Electron microscopy of bacteria. Nature, Lond., $160,864$.

Brieger, E. M. \& Robinow, C. F. (1947). Demonstration of chromatinic structures in avian tubercle bacilli in the early stages of development. J. Hyg., Camb., 45, 413-16.

Burdon, K. L. (1946). Fatty material in bacteria and fungi revealed by staining fixed slide preparations. J. Bact. 52, 665-78.

Epstein, G. W., Ravich-Birger, E. D. \& Svinkina, A. (1936). Contributions to the cytology of the tubercle bacillus. G. Batt. Immun. 16, 1-27.

Kuieneberger-Nobel, E. (1947). The life cycle of sporing Antinomyces as revealed by a study of their structure and septation. J. gen. Microbiol. 1, 22--32. 
KNAysi, G. (1942). The demonstration of a nucleus in the cell of a Staphylococcus. J. Bact. 43, 365-85.

Porter, K. R. \& Yegian, D. (1945). Some artefacts encountered in stained preparations of tubercle bacilli. J. Bact. 50, 563-75.

Rosinow, C. F. (1945). Addendum to: Dubos, R. J. The Bacterial Cell. Harvard Univ. Press.

\section{EXPLANATION OF PLATE}

Fig. 1. C. diphtheriae (gravis), Neisser's stain. $\times 3000$.

Fig. 2. C. diphtheriae (gravis), tannic-acid-violet. $\times 3000$.

Fig. 3. C. diphtheriae (gravis), acid-Giemsa. $\times 3000$.

Fig. 4. C. diphtheriae (intermedius), acid-Giemsa. $\times 3000$.

Fig. 5. Corynebacterium sp. (human vaginal origin), tannic-acid-violet. $\times 3000$.

Fig. 6. Corynebacterium sp. (human vaginal origin), acid-Giemsa. $\times 3000$.

Fig. 7. M. tuberculosis (human), acid-Giemsa. $\times 3000$.

Fig. 8. M. tuberculosis (cold-blooded), acid-Giemsa. $\times 3000$.

Fig. 9. M. tuberculosis (cold-blooded), tannic-acid-violet. $\times 3000$.

Fig. 10. M. phlei, tannic-acid-violet. $\times 3000$.

(Received 23 April 1948)

Adpendum (17 November 1948). In the 1948 edition of Bergey's Manual of Determinative Bacteriology (6th ed. Baltimore: Williams and Wilkins) the Corynebacteria are separated from the Mycobacteria and placed with the Eubacteria. The cytological findings in the present paper are even more at variance with this classification than with that in the 1939 edition. 
Journal of General Microbiology, Vol. 3, No. 1

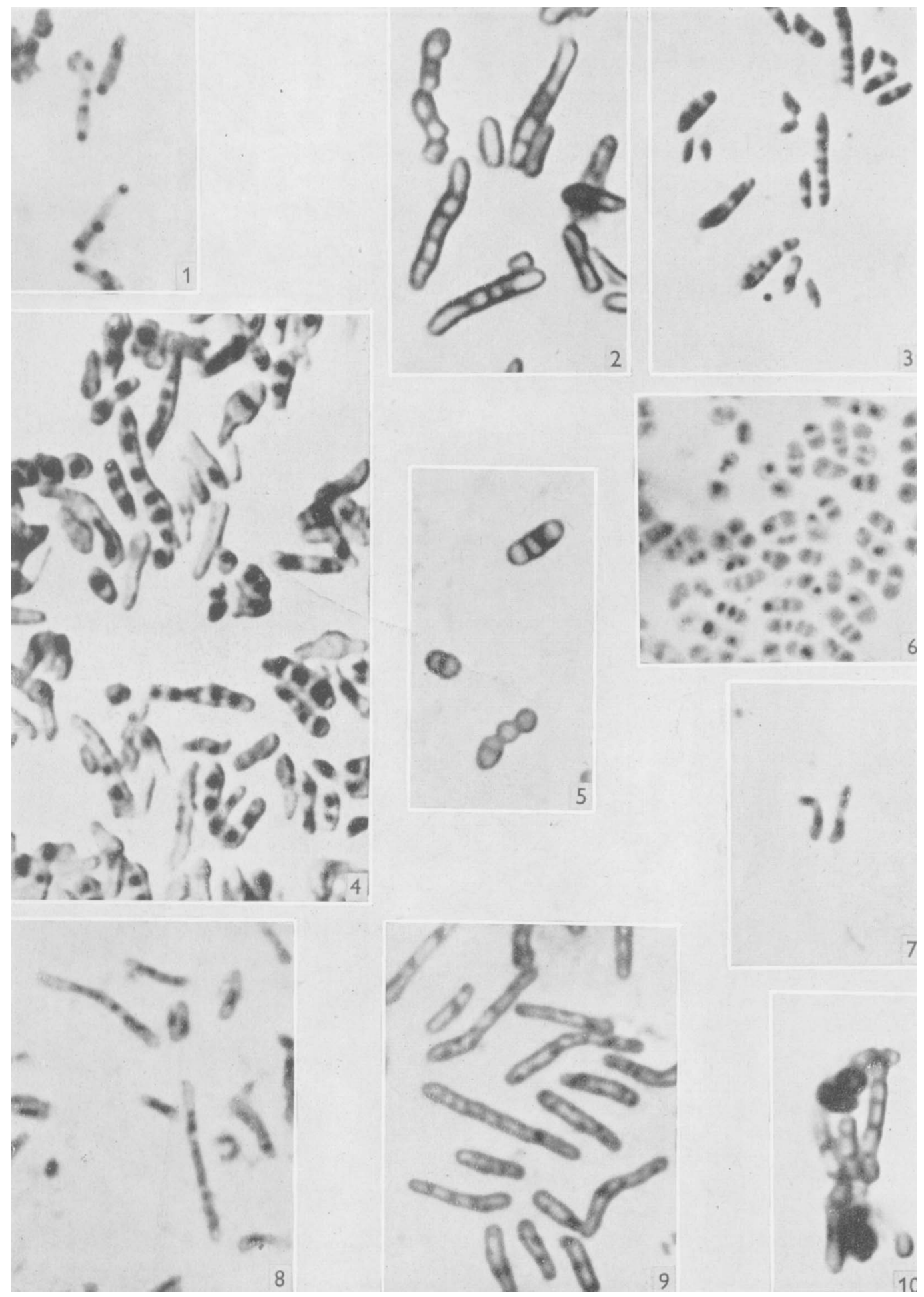

Figs. 1-10

K. A. Bisset-Obsiervations upon the cytology of Corynebacteria and Mycobacteria, Plate 1 